\title{
Processo de formação das representações sociais sobre transexualidade dos profissionais de saúde: possíveis caminhos para superação do preconceito
}

\author{
Training process of the social representations on transsexuality \\ among health professionals: possible ways to overcome prejudice
}

Adelyany Batista dos Santos ${ }^{1}$

Helena Eri Shimizu ${ }^{2}$

Edgar Merchan-Hamann²

${ }^{1}$ Secretaria de Estado de Saúde do Distrito Federal. Área especial número 38Setor Central, Gama. 71000-000 Brasília DF Brasil.

adelyany@hotmail.com

${ }^{2}$ Departamento de Saúde

Coletiva, Faculdade

de Ciências da Saúde,

Universidade de Brasília.

\begin{abstract}
The scope of this paper is to identify and analyze the structure of social representations of health professionals about transsexuality. The theoretical and methodological benchmark used was the structural approach to social representations developed by Jean-Claude Abric. 128 health professionals from 22 health units in the State Health Department of the Federal District of Brasilia were interviewed. Data collection consisted of the application of a semi-structured questionnaire based on the technique of free association with the key word "transsexuality." The data were processed using EVOC 2000 software. The profile of the subjects reveals the predominance of female participants and professionals in the field of nursing. The terms "sex change" and "prejudice" seem to feature as the central nucleus, and "transformation," "option," "respect" and "acceptance" are the peripheral systems of representation.
\end{abstract}

Key words Gender and health, Health personnel, Health policy
Resumo O objetivo deste artigo é identificar e analisar a estrutura das representações sociais dos profissionais de saúde sobre transexualidade. $O$ referencial teórico-metodológico utilizado na pesquisa foi a abordagem estrutural das representações sociais, desenvolvida por Jean-Claude Abric. Foram sujeitos da pesquisa 128 profissionais de saúde de 22 unidades da Secretaria de Estado de Saúde do Distrito Federal. A coleta de dados consistiu na aplicação de questionário semiestruturado baseado na técnica de associação livre com o termo indutor "transexualidade". Os dados foram tratados no software EVOC 2000. O perfil dos sujeitos indica a predominância de participantes do sexo feminino e de profissionais da área da enfermagem. Os termos "mudança de sexo" $e$ "preconceito" aparecem provavelmente compondo o núcleo central, e "transformação", "opção", "respeito" e "aceitação" os sistemas periféricos da representação.

Palavras-chave Gênero e saúde, Pessoal de saúde, Política de saúde 


\section{Introdução}

Nos últimos anos no Brasil, a transexualidade tem sido objeto de políticas públicas, principalmente no campo da saúde. Contudo, pode ser considerado um universo ainda pouco conhecido, dada a existência de múltiplas dimensões que o compõe e o configuram como um fenômeno complexo. Uma dessas dimensões na área da saúde é a forma como a transexualidade é percebida pelos profissionais, pois essa percepção pode influenciar na direção e na qualidade da atenção integral à saúde.

A integralidade é um dos princípios filosóficos e organizativos do Sistema Único de Saúde (SUS). Supõe que o sujeito seja acolhido e atendido, considerando todos os seus aspectos de saúde e dimensões de vida. Entendido como um conceito muito abrangente, a integralidade em saúde pode ser considerada como o cuidado oferecido a indivíduos, grupos e coletividades, levando em conta seus contextos sócio-históricos, políticos, familiares e ambientais ${ }^{1}$.

Em novembro de 2009, o Conselho Nacional de Saúde (CNS) aprovou a Política Nacional de Saúde Integral da População Lésbica, Gay, Bissexual, Travesti e Transexual (LGBT), elaborada pelo Comitê Técnico para Gays, Lésbicas, Transgêneros e Bissexuais, órgão consultivo ligado à Secretaria de Gestão Estratégica e Participativa (SGEP), instituído em 2004 pelo Ministério da Saúde (MS). O objetivo geral dessa política é promover a saúde integral da população LGBT, eliminando a discriminação e o preconceito institucional, contribuindo para a redução das desigualdades e para a consolidação do SUS como sistema universal, integral e equânime² .

Não obstante aos avanços alcançados nos últimos anos, o paradigma médico hegemônico atual considera a transexualidade um transtorno, que necessita de tratamento, intervenção e correção ${ }^{3}$, obedecendo a uma lógica de normalidade e de linearidade entre sexo, gênero e sexualidade. Uma crítica a essa concepção questiona essa linearidade e afirma que existem diversas formas de trânsitos entre os gêneros, e esse movimento não se prende de forma predestinada à estrutura do corpo 4 .

Cerqueira-Santos e DeSouza ${ }^{5}$ afirmam que há o estigma generalizado da população em relação às minorias sexuais, especialmente aos transgêneros, inclusive por profissionais com boa formação. Goffman ${ }^{6}$ denomina estigma o processo de perceber algo estranho diante de nós a partir do seu atributo específico, e não da sua totalida- de, podendo assim surgir elementos que o inclua numa categoria de não desejável, ruim, menor. Dentro da lógica da normalidade, tudo que se apresenta como diferente pode ser classificado como "anormal".

$\mathrm{Na}$ atenção à saúde, a prática profissional aqui é entendida como potencialmente educativa. Dentro de um conceito amplo de saúde, essa prática deve buscar a melhoria da qualidade de vida das pessoas, por meio da superação das desigualdades sociais e do despertar crítico da sociedade, aperfeiçoando a compreensão da realidade, visando à sua transformação ${ }^{7}$. O resultado esperado é o fortalecimento da apropriação por parte da população sobre seu processo saúdedoença, de forma autônoma, participativa, pautada nas ideias de cidadania e democracia. Esse processo educativo deve privilegiar relações de comunicação que sejam pautadas no diálogo, na horizontalidade, no respeito à intersubjetividade, de forma a garantir que os discursos dos sujeitos possam acontecer no espaço da conquista da cidadania e da geração de autonomiå.

Todavia, levantamos a hipótese, de que o cuidado integral às pessoas transexuais é um desafio a ser alcançado nos serviços de saúde. Diante do exposto, surgem algumas questões: como profissionais de saúde percebem o fenômeno da transexualidade? Quando se deparam com sujeitos que não estão claramente situados nas normas de gênero e sexo vigentes, percebem esses sujeitos em sua totalidade ou a partir de um atributo específico? De que forma essa percepção condiciona e/ou determina suas práticas em saúde? Certamente não se pretende nesse artigo responder a essas questões de forma definitiva, ou discutir em profundidade a questão da transexualidade, mas provocar reflexões sobre quais aspectos devem ser observados na relação entre profissional de saúde e indivíduo atendido, principalmente quando este faz parte de um grupo populacional estigmatizado.

O objetivo deste artigo é identificar e analisar a estrutura das representações sociais dos profissionais de saúde sobre transexualidade, com a intenção de compreender aspectos fundamentais da relação profissional com o sujeito dá atenção à saúde, na construção de uma prática que busca a integralidade como um dos princípios dessa atenção.

\section{Transexualidade a partir do século XX}

A transexualidade enquanto objeto de preocupação da ciência e da medicina, tal qual é conhecida atualmente, foi "construída" no século 
XX principalmente pelas descobertas e melhorias tecnológicas sobre hormônios e técnicas cirúrgicas, e por mudanças epistemológicas e políticas ocorridas principalmente no século XVIII 9 .

A palavra "transexual-psíquico" foi utilizada em 1910 no livro Die Tranvestiten do alemão Magnus Hirschfeld para se referir a questões relacionadas ao travestismo e à homossexualidade ${ }^{9,10}$. Em 1912, o mesmo autor cita uma intervenção cirúrgica e hormonal de redefinição sexual ${ }^{10}$.

Em 1949, Cauldwell publica um estudo de caso de um transexual masculino, onde cita algumas características específicas de transexuais, diferenciando-os de travestis e homossexuais, e, a partir da década de 1950, as publicações que surgem defendem a transexualidade como um fenômeno específico? .

Ao longo das décadas de 1960 e 1970, essa ideia da transexualidade como um fenômeno específico ganha visibilidade com o surgimento de associações internacionais que se dedicam a discutir o diagnóstico diferenciado e seu tratamento. Harry Benjamin, endocrinologista alemão emigrado nos Estados Unidos da América, defendeu que a cirurgia seria a única terapêutica possível nesse caso ${ }^{9}$.

John Money, professor de psicopediatria, defendeu a tese de que o gênero e a identidade sexual são modificáveis nos primeiros meses de vida, e que a transexualidade seria um distúrbio cerebral que alteraria a imagem sexual do corpo, de forma incompatível com os órgãos genitais do nascimento ${ }^{9}$.

Nas décadas de 1980 e 1990, autores como Michel Foucault e Judith Butler produzem críticas a esse modelo patologizante de compreensão, construindo a noção de sexo não como algo naturalmente essencial e dimórfico (masculino e feminino), mas sim um produto do discurso sobre o corpo ${ }^{10}$.

A condição de sofrimento intenso, desconforto e inadequação, por estar no corpo errado do ponto de vista do sexo anatômico, com ausência de distúrbios delirantes ou de bases orgânicas, é descrita na $10^{a}$ revisão da Classificação Internacional de Doenças (CID - 10), no código F 64.0, como Transtorno de Identidade Sexual - Transexualismo. O manual de diagnósticos da Associação Americana de Psiquiatria, em sua IV revisão (DSM - IV), classifica essa condição como Transtorno da Identidade de Gênero, com o código F64.x.

Por meio da Resolução no 1.482/97, o Conselho Federal de Medicina (CFM) brasileiro reconheceu, a título experimental, a cirurgia de transgenitalização e outros procedimentos como tratamento dos casos de transexualismo. Em 2002, a Resolução no 1.652 do CFM revoga a anterior, retirando o caráter experimental dos casos de adequação do fenótipo masculino para o feminino, mas mantém as condições anteriormente definidas, que é ser maior de idade, cumprir o prazo mínimo de dois anos de acompanhamento terapêutico, e ser diagnosticado como transexual.

Em 2008, o Ministério da Saúde normatizou os procedimentos do processo transexualizados por meio da Portaria GM no. 1.707, de 18 de agosto, determinando diretrizes técnicas e éticas para esse processo no SUS. Essa portaria reconhece que a orientação sexual e a identidade de gênero são determinantes e condicionantes da situação de saúde, e que o sofrimento gerado pela sensação de inadaptação em relação ao sexo anatômico dos usuários transexuais devem ser acolhidos e tratados pelo SUS, obedecendo aos princípios da universalidade, integralidade e equidade da atenção.

Arán et al. ${ }^{11}$ evidenciam a necessidade de considerar a transexulidade para além dos procedimentos específicos do processo transexualizador, sendo a questão da representação social, que pode estigmatizar essa parcela da população, mais complexa e danosa.

\section{As Representações Sociais}

A Teoria das Representações Sociais, proposta por Moscovici ${ }^{12}$ mostra-se profícua para compreender um objeto complexo que abarca múltiplas dimensões como a transexulaidade.

As representações sociais são definidas como sistemas teóricos do senso comum onde atores sociais compreendem, interpretam seu ambiente natural e social, e nele se situam ${ }^{13,14}$. Podem ser entendidas como "teorias coletivas" sobre o que é percebido, a fim de dar compreensão a objetos, estabelecer comunicação, orientar e determinar condutas, utilizando um sistema de linguagem que aproxima esse objeto do que já é familiar. Essa construção teórica acaba definindo a identidade de grupos sociais e permite o acesso às dimensões simbólicas, culturais e práticas dos fenômenos sociais" ${ }^{15}$. Considerada uma "grande teoria”, teve vários desdobramentos, dentre eles a abordagem estrutural.

A abordagem estrutural das representações sociais foi desenvolvida por Jean-Claude Abric, que propôs em 1976 pela primeira vez a teoria do núcleo central como organizador das representações $^{12}$. 
Essa abordagem se dedica especialmente aos aspectos sociocognitivos da representação e a forma como são estruturados em torno de sistemas centrais e periféricos. A premissa dessa abordagem é que toda representação é organizada em torno de um núcleo central, elemento essencial da representação, composto por elementos mais estáveis, historicamente definidos, onde a alteração desse núcleo transformaria completamente a representação. Os sistemas periféricos contêm elementos menos estáveis, flexíveis, passíveis ao contexto das práticas sociais ${ }^{12,16}$.

Os métodos de pesquisa do núcleo central podem ser classificados em dois grupos principais: 1 - levantamento dos possíveis elementos do núcleo central, que evidencia a saliência e a conexão desses elementos, podendo-se utilizar as técnicas de associação livre e de hierarquização de itens, onde os resultados apenas auxiliam na formulação de hipóteses, mas que se constitui etapa indispensável para compreensão do núcleo central; 2 - identificação dos elementos que efetivamente compõem o núcleo central, a partir das cognições levantadas, onde, além do levantamento dos possíveis elementos constituintes do núcleo central, realiza-se testes de centralidade para verificação e confirmação dessa evidência ${ }^{16}$.

O presente estudo se propõe a fazer o levantamento dos possíveis elementos do núcleo central das representações sociais dos profissionais de saúde sobre transexualidade a fim de subsidiar a formulação de hipóteses sobre o tema.

\section{Métodos}

Trata-se de um estudo exploratório sobre representações sociais.

Os locais de pesquisa selecionados foram as oito unidades de saúde da Secretaria de Estado de Saúde do Distrito Federal (SES-DF), que são Centros de Referência em DST e AIDS, e um Centro de Saúde de cada Regional de Saúde da SES-DF - somando mais 15 unidades -, determinados por sorteio aleatório, totalizando 23 unidades de saúde. Uma unidade de saúde recusou a participação na pesquisa.

Foram definidos como sujeitos da pesquisa, médicos, enfermeiros, e auxiliares ou técnicos em enfermagem. A opção por essas categorias se deu basicamente por serem os profissionais que estão em maior quantidade nas unidades de saúde e geralmente são os que primeiro têm contato com as pessoas que chegam ao serviço. Inicialmente, foi definido que seriam convidados três profissionais de cada categoria, que estivessem disponíveis no momento da coleta de dados, mas esse número variou de acordo com a realidade de cada unidade de saúde selecionada. Então, foram convidados 150 profissionais, sendo que 128 concordaram com a participação e 16 recusaram. Houve seis perdas, que corresponde a $4 \%$ da amostra.

A coleta de dados foi realizada pela própria pesquisadora entre os meses de agosto e outubro de 2011. Consistiu na aplicação de questionário, previamente testado, semiestruturado, baseado na técnica de associação livre, onde era solicitado ao participante que escrevesse pelo menos quatro palavras ou expressões que lhes ocorressem imediatamente em relação ao termo indutor "transexualidade". Em seguida, deveriam listar, em ordem de importância, as três palavras ou expressões consideradas mais importantes, e, por fim, descrever o significado do termo considerado mais importante. Também foi utilizado diário de campo, onde puderam ser registradas pela pesquisadora observações durante o período de aplicação do instrumento, como afirmações, dúvidas e outras expressões dos profissionais de saúde em relação à pesquisa.

Os dados coletados foram processados pelo software EVOC 2000, que calculou as relações entre as frequências e as ordens de evocação, considerando 16 a frequência intermediária e 3.7 a ordem média de frequência, gerando o quadro de quatro casas. Nesse quadro, o quadrante superior esquerdo apresenta as palavras mais frequentes e mais prontamente evocadas, o que indica que provavelmente fazem parte do núcleo central da representação. No quadrante inferior esquerdo aparecem os termos com frequência menor, mas prontamente evocados, e no superior direito, os muitos frequentes, mas não tão prontamente citados. Esses dois quadrantes indicam as palavras que possivelmente pertencem ao sistema periférico das representações e estão mais próximos ao núcleo central. Por fim, o quadrante inferior direito indica os termos que foram pouco frequentes e menos prontamente evocados, indicando a periferia distante ${ }^{17}$.

Para testar a centralidade dos termos que aparecem como provavelmente pertencentes ao núcleo central, foi calculada a queda de frequência entre os termos apresentados no primeiro quadrante do quadro de quatro casas e os termos hierarquizados como os mais importantes pelos participantes da pesquisa.

Para a análise foram considerados o quadro de quatro casas, onde é possível identificar os su- 
postos núcleo central e sistemas periféricos das representações, e as descrições dos significados das principais palavras e o significado das palavras.

$\mathrm{O}$ projeto de pesquisa foi submetido ao Comitê de Ética em Pesquisa da Fundação de Ensino e Pesquisa em Ciências da Saúde (FEPECS), seguindo todas as recomendações éticas vigentes, aprovado em 8 de junho de 2011.

\section{Resultados}

No perfil sociodemográfico dos sujeitos da pesquisa (Tabela 1) pode-se notar a predominância de participantes do sexo feminino, casados ou vivendo em união estável $(51,1 \%)$, católicos e pardos. A idade variou entre 24 e 67 anos (mediana

Tabela 1. Perfil sociodemográfico dos sujeitos da pesquisa.

\begin{tabular}{|c|c|c|c|}
\hline \multirow[t]{2}{*}{ Variável } & \multirow[t]{2}{*}{ Categoria } & \multicolumn{2}{|c|}{$\begin{array}{c}\text { Total } \\
(n=128)\end{array}$} \\
\hline & & $\mathbf{N}$ & $\%$ \\
\hline \multicolumn{4}{|l|}{ Sexo } \\
\hline & Masculino & 21 & 16,4 \\
\hline & Feminino & 104 & 81,3 \\
\hline & Sem resposta & 3 & 2,3 \\
\hline \multicolumn{4}{|c|}{ Idade (em anos) } \\
\hline & $20-29$ & 6 & 4,5 \\
\hline & $30-39$ & 38 & 29,7 \\
\hline & $40-49$ & 42 & 32,7 \\
\hline & $50-59$ & 29 & 22,7 \\
\hline & $60 \mathrm{ou}+$ & 5 & 3,9 \\
\hline & Sem resposta & 8 & 6,2 \\
\hline \multicolumn{4}{|l|}{ Estado civil } \\
\hline & Solteiro & 30 & 23,4 \\
\hline & Casado & 59 & 46,1 \\
\hline & União estável & 14 & 11,0 \\
\hline & Separado/Divorciado & 18 & 14,1 \\
\hline & Viúvo & 3 & 2,3 \\
\hline & Sem resposta & 4 & 3,1 \\
\hline \multicolumn{4}{|l|}{ Religião } \\
\hline & Católica & 68 & 53,1 \\
\hline & Evangélica & 21 & 16,4 \\
\hline & Espírita & 8 & 6,3 \\
\hline & Outras & 20 & 15,6 \\
\hline & Não tem & 7 & 5,5 \\
\hline & Sem resposta & 4 & 3,1 \\
\hline \multicolumn{4}{|l|}{ Raça/cor } \\
\hline & Branco (a) & 42 & 32,8 \\
\hline & Preto (a) & 8 & 6,3 \\
\hline & Pardo (a) & 70 & 54,7 \\
\hline & Amarelo (a) (asiático) & 1 & 0,8 \\
\hline & Indígena & 2 & 1,6 \\
\hline & Outro (a) ou sem resposta & 5 & 3,9 \\
\hline
\end{tabular}

43, média 42), predominando a faixa etária de 30 a 49 anos $(62,4 \%)$. As outras religiões citadas foram espiritualista, protestante, religiosidade, presbiteriana, cristã, adventista do $7^{\circ}$ dia, messiânica e budista.

Quanto às características profissionais (Tabela 2), o número de participantes de unidade que são Centro de Referência em DST e AIDS é relativamente aproximado àqueles que não são, ou seja, que são unidades básicas de saúde. A grande maioria $(80,5 \%)$ é de profissionais da enfermagem, sendo que a maior parte são auxiliares ou técnicos em enfermagem, seguidos de enfermeiros e, em menor quantidade, médicos. Aproximadamente 69\% referem ter mais de 10 anos (variando de 1 a 41, com mediana de 16, e média de 18) de experiência profissional e praticamente a mesma quantidade afirma já ter atendido uma pessoa transexual ao longo de sua carreira profissional.

Na técnica de associação livre foram evocadas ao todo 676 palavras e/ou expressões, sendo 463 termos diferentes.

Não foram observadas diferenças significativas nas evocações dos profissionais de saúde, nem mesmo em relação às categorias profissionais ou em relação ao local de trabalho.

Como podem ser observados na Tabela 3, os termos "mudança de sexo" e "preconceito" aparecem no primeiro quadrante, possivelmente compondo o núcleo central da representação sobre transexualidade.

Quando os participantes descrevem o significado do termo que consideram mais importantes, descrevem "mudança de sexo" como adequação do corpo à cabeça, sendo o fato mais importante para a pessoa transexual se sentir completa. Por não estar satisfeita com o próprio sexo, com o próprio corpo, a pessoa buscaria assumir um lado diferente do biológico, a partir de uma necessidade física da mudança corporal, principalmente do órgão genital, para expressar suas tendências e satisfações físicas/psicológicas. Nessa perspectiva seriam considerados anormais, diferentes, alvo de preconceitos por parte da sociedade. Além disso, não seriam vistos de forma livre, tendo poder sobre seu próprio corpo, e sujeitos de direitos e deveres como qualquer cidadão comum em relação à saúde, educação, lazer e cultura.

O termo "preconceito" é descrito como o julgamento pejorativo das pessoas transexuais por parte da sociedade por não aceitar as diferenças, não entender o porquê e por ser olhado como algo anormal. Na fala dos participantes assinala-se para o não respeito dos seus direitos e preferências, o que causa solidão e até infelici- 


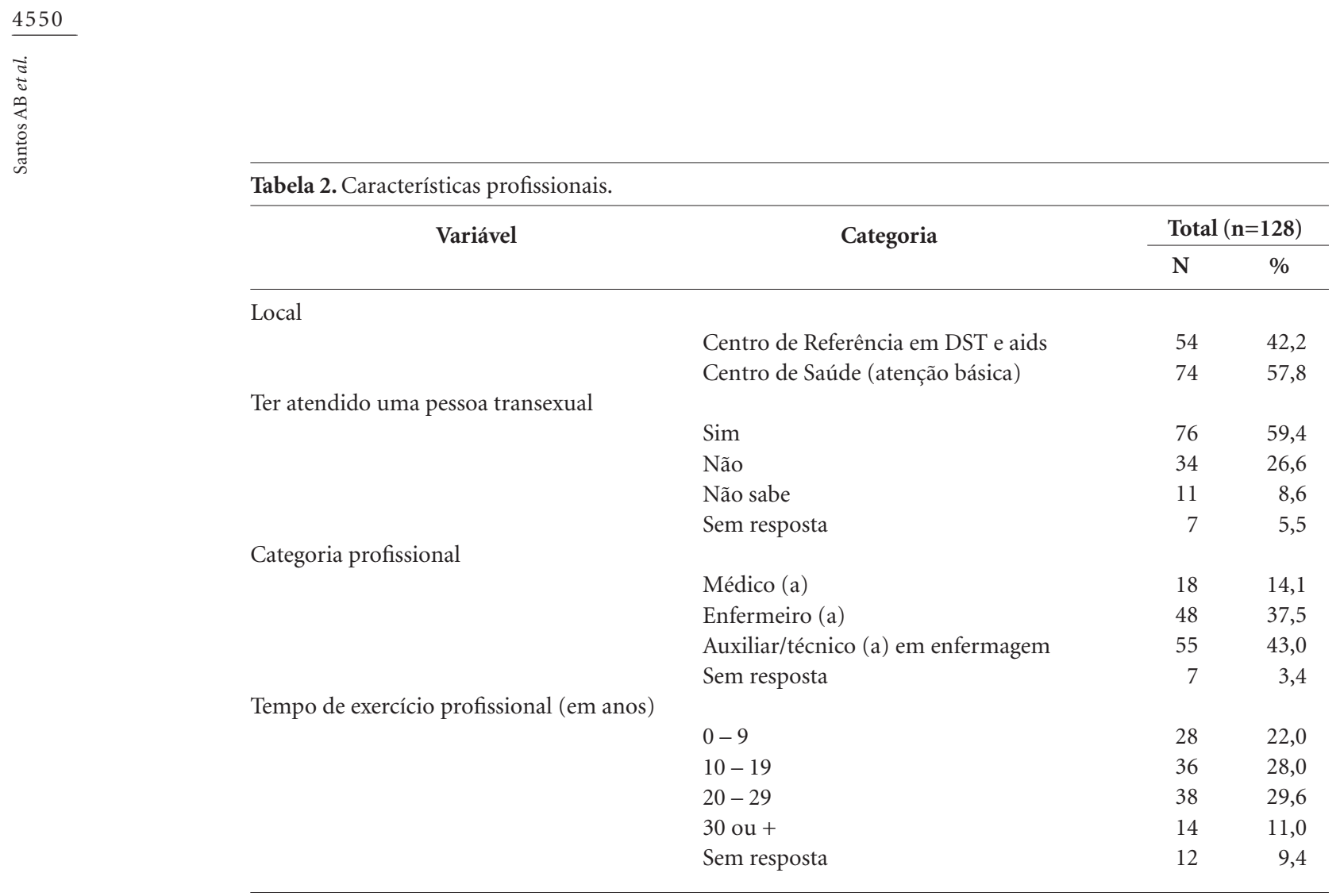

Tabela 3. Quadro de quatro casas.

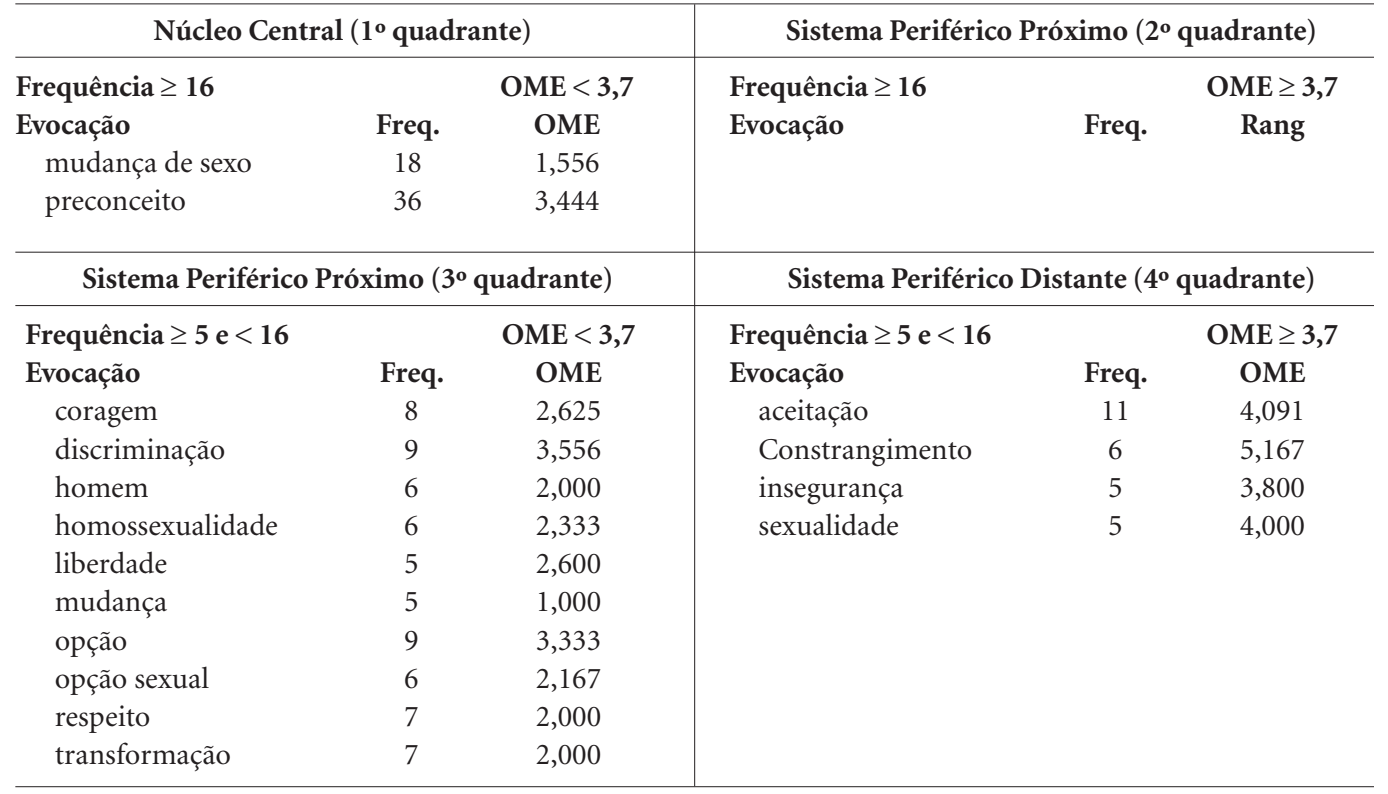

dade à pessoa discriminada. O ser humano ainda é muito preconceituoso em relação ao transexualismo. Ainda é muito grande a dificuldade de lidar com questões relacionadas à sexualidade. É um desafio para uma sociedade conservadora e religiosa conviver e se relacionar respeitando as diferenças. Também foi citado que é confundida com a homossexualidade, mas que é um conceito muito mais abrangente, que demanda assistência adequada à sua dimensão. 
No terceiro quadrante estão os termos que provavelmente fazem parte do sistema periférico mais próximo do núcleo central. A transexualidade é relacionada com a "transformação" de um corpo de um determinado sexo em outro de outro sexo, que além de física é psíquica e social, uma "mudança" contínua no comportamento e conflitos internos no sentido de melhorar. A pessoa quer ser o que acha que é, de acordo com seus sentimentos. Nos depoimentos, declara-se que vivemos em uma sociedade extremamente preconceituosa, e que em nosso país as pessoas ainda não evoluíram e por isso há "discriminação" com os transexuais. Consideram que essas pessoas devem ter muita "coragem" para se assumirem sem se preocupar com outros.

No sistema periférico, a transexualidade também é representada como uma opção. Os termos "opção" e "opção sexual" são descritos como uma opção de vida, motivada por demandas subjetivas ou do meio social em que a pessoa está inserida. E desde que seja de um adulto e não haja nenhum comprometimento físico, essa opção deve ser respeitada, pois se trata do direito de decidir sobre a própria sexualidade. A partir dessa escotha, surgem conflitos entre a realização dos desejos e a 'inadequação social', e resistência de familiares. A opção envolve prazeres e cruzes como tudo na vida. Esse tipo de comportamento acontece por falta de crença em um deus superior.

A palavra "respeito" é descrita como a procura por aceitar e compreender o indivíduo com suas qualidade e diferenças, pois cada um tem direito sobre a própria vida. É respeitar o próximo independente da sua sexualidade, cor ou idade. Por se tratar de um tema pouco conhecido, uma postura de respeito é fundamental.

$\mathrm{Na}$ periferia mais distante, o termo "aceitação" é apresentado com duas ideias distintas. Uma diz respeito à necessidade de aceitar o outro como ele é, pensa, age, vive e tudo que lhe é intrínseco, abrindo mão de atitudes moralizantes, que não consideram a individualidade do ser humano. Aprender a viver com o diferente sem discriminá-lo, criticá-lo. A outra tem relação com a autoaceitação. Conseguir estar bem da maneira que consegue se vir, aceitar-se, ter paz interior. Estar de bem consigo mesmo(a) enfrentando a situação vivenciada de forma a conservar a dignidade e moral.

\section{Discussão}

Em relação ao perfil dos participantes, a grande quantidade de mulheres chama a atenção. Cerqueira-Santos e DeSouza ${ }^{5}$ concluem, a partir de análise sobre preconceito e discriminação contra minorias sexuais, que mulheres tendem ser menos preconceituosas que homens.

Mais da metade dos profissionais declaram ter atendido uma pessoa transexual pelo menos uma vez durante a trajetória profissional. Esse dado é interessante, e ao mesmo tempo contraditório, pois não se sabe como esses profissionais identificaram a pessoa dita transexual. Sendo a transexualidade uma forma autodeclarada de se identificar, não foi possível saber se esses profissionais, de fato, solicitaram uma declaração em relação ao sexo, gênero ou identidade sexual, ou se foi uma dedução. Poucos profissionais responderam não saber se já atenderam uma pessoa transexual.

Quando se observa as expressões que supostamente fazem parte do núcleo central das representações, o termo "mudança de sexo" é o mais frequente e mais prontamente citado. Essa noção está ancorada na tese do corpo difórmico a partir de diferenças sexuais e na linearidade entre o sexo, o corpo e o gênero, e na diferença entre o que é biológico e o que é psicológico, desenvolvida principalmente no século XIX. Em momentos históricos anteriores, o corpo já foi percebido como isomórfico, ou seja, existia apenas um corpo, onde as diferenças apenas o colocavam em maior ou menor grau de perfeição ${ }^{18}$. Essa é a ideia que fundamenta a classificação da transexualidade como uma patologia, pois, em princípio, uma pessoa que nasce com vagina, deve ser reconhecida como mulher, e normalmente irá desempenhar um papel feminino na sociedade. Quando isso não ocorre, quando os corpos não obedecem à lógica binária homem/pênis/masculino - mulher/vagina/feminino, surgem processos marcados por conflitos, dores e medos, uma vez que ameaçam a chamada "natureza humana", ao mesmo tempo em que produzem possibilidades de transformações dessas normas?.

Mas essa patologização não questiona se há problemas nas normas de gênero, consideradas tão fixas. Não considera que esse sofrimento intenso e esse desconforto podem ser produzidos pela própria norma, impedindo que as pessoas desempenhem suas funções ${ }^{4}$.

Bento ${ }^{9}$ afirma que, antes mesmo de nascer, o corpo já está construído pela linguagem e por um campo de discurso que desenha os limites de 
normalidade do sujeito. O gênero é, portanto, uma produção tecnológica, uma repetição estilizada de atos que não se restringe aos limites do corpo biológico. Não que apenas a cultura produza a materialidade do corpo, mas esse corpo só tem uma sexualidade reconhecida, só se torna sexualmente legível a partir de uma interpretação que é cultural e social ${ }^{4}$.

Um dos aspectos das representações que os profissionais de saúde têm da transexualidade se aproxima do entendimento de que existem essencialmente diferenças que definem dois sexos, e o não cumprimento das expectativas que cada um deles carrega, provoca conflito e confusão.

Pode-se notar que o segundo termo mais frequente e prontamente citado, "preconceito", confirma a ideia de que quem, por qualquer razão, não cumpre um norma socialmente ou culturalmente definida, sofre algum tipo de rejeição e estranheza. Tanto por desconhecimento como por não aceitação das diferenças, a sociedade provoca sofrimento às pessoas discriminadas. Interessante observar que os profissionais não evidenciam que esse preconceito existe no espaço e nas relações dos serviços de saúde, mas estende esse processo à sociedade como um todo. O preconceito não e percebido como próprio, mas há um deslocamento do preconceito como algo que faz parte da realidade do 'outro', da sociedade. Isto indica um distanciamento em relação ao cotidiano do transexual, incidindo no fato de ser incipiente a definição da representação social.

A transexualidade possivelmente não se constitui objeto de representação social no grupo estudado. Para uma questão se tornar objeto de representação social é necessário que os atores sociais compreendam, interpretem e se situem em relação à realidade apresentada ${ }^{13}$. $\mathrm{O}$ tema transexualidade foi trazido ao cenário político e de senso comum, principalmente, pelo movimento LGBT apenas há alguns anos. $\mathrm{O}$ fato de transexualidade ser confundida como sinônimo de homossexualidade, por exemplo, evidencia o distanciamento dos profissionais de saúde em relação ao tema.

Shelley ${ }^{19}$ demonstra, por meio de pesquisa própria e de citações de outras investigações, que provavelmente é nos serviços de saúde que a chamada "transfobia", ou seja, o repúdio a pessoas trans, seja mais evidente, tanto em serviços especializados para o processo transexualizador, como em serviços de cuidados básicos e de emergência.

Nos sistemas considerados como provavelmente periféricos, termos como "mudança", "transformação" e "opção", atribuem à questão caráter demasiadamente individual e subjetivo. É como se cada indivíduo sozinho fosse responsável por suas próprias escolhas, e pelas consequências advindas delas, sem considerar questões mais amplas de sociedade e cultura.

As expressões "respeito" e "aceitação" indicam provavelmente para um entendimento de que todos devem ser respeitados nas suas escolhas, diferenças, e formas de existir, mas não provoca nenhuma mudança significativa nos elementos centrais da representação, ao contrário, o protegem.

Apesar de avanços, como o direito ao uso do nome social, o acesso ao sistema de saúde ainda é precário, seja nos serviços especializados que atendem transexuais, ou em qualquer outro serviço, que prioritariamente deve ter como porta de entrada a atenção básica. Construir e garantir a efetiva atenção integral à saúde é um desafio ${ }^{20}$.

Outro desafio permanente dos serviços de saúde é substituir efetivamente a atitude normatizadora das práticas educativas por uma atitude emancipadora. Para o profissional passar de detentor do saber para mediador do saber é um longo caminho a ser trilhado. Pensar qual o contexto mais favorável à simetria entre educador e educando, à efetiva problematização e à criatividade individual e comunitária na busca de soluções, e escolhê-los como estratégia frente a outros mais facilmente modeladores, é um modo de enfrentar este desafio ${ }^{21}$.

É necessário reconhecer as limitações de em estudo como este, principalmente porque diz respeito a um tema tão complexo, e, como disse um dos profissionais durante a coleta de dados, difícil de falar sobre. Algumas pessoas demonstraram inquietação ao preencher o questionário e outras, resistência em participar, apresentando dúvidas sobre o tema, fazendo perguntas, declarando que se trata de um tema muito polêmico, ou preferindo não participar por motivos religiosos. Seria necessário também validar, por meio de outras técnicas, a estrutura da representação social que os profissionais de saúde têm sobre a transexualidade, pois este estudo apenas evidencia prováveis saliências e aponta caminhos para essa compreensão.

\section{Considerações finais}

É fundamental compreender como os profissionais de saúde percebem as pessoas que demandam cuidados em saúde, pois essa percepção apontará direções para a construção de uma prá- 
tica profissional comprometida com a construção e a consolidação do SUS.

Populações estigmatizadas e discriminadas merecem atenção especial, pois o próprio estigma se coloca como um fator de vulnerabilidade em saúde, na medida em que pode comprometer o acesso ao serviço e a qualidade da atenção prestada.

Formação profissional e educação permanente devem fazer parte da discussão sobre a atenção integral à saúde, que, por sua vez, deve favorecer o contato com as diversas realidades existentes, $\mathrm{e}$ a criação de espaços de diálogo entre os profissionais de saúde e a população atendida.

Evidenciar o tema transexualidade nos serviços de saúde é fundamental para construção de representações sociais sobre essa questão, o que pode se constituir como ação estratégica para efetiva implementação das políticas públicas e sociais relacionadas.

\section{Colaboradores}

AB Santos, E Merchan-Hamann e HE Shimizu participaram igualmente de todas as etapas de elaboração do artigo.

\section{Referências}

1. Machado MF, Monteiro EM, Queiroz DT, Vieira NF, Barroso MG. Integralidade, formação de saúde, educação em saúde e as propostas do SUS - uma revisão conceitual. Cien Saude Colet 2007; 12(2):335-342.

2. Brasil. Ministério da Saúde (MS). Política Nacional de Saúde Integral de Lésbicas, Gays, Bissexuais, Travestis e Transexuais. Brasília: MS; 2010.

3. Ramsey G. Transexuais: perguntas e respostas. São Paulo: Summus; 1998.

4. Butler J. Desdiagnosticando o gênero. Physis 2009; 19(1):95-126.

5. Cerqueira-Santos E, DeSouza E. Cultura e Produção das Diferenças: estereótipos e preconceito no Brasil, Espanha e Portugal. In: Cerqueira-Santos E, DeSouza E, organizadores. Preconceito e Discriminação contra Minorias Sexuais: O Caso da Homofobia. Brasília: Technopolitik; 2011. p. 247-272.

6. Goffman E. Estigma: notas sobre a manipulação da identidade deteriorada. Rio de Janeiro: Zahar Editores; 1982.

7. Sabóia VM. Educação em Saúde: a arte de talhar pedras. Niterói: Intertexto; 2003.

8. Freire P. Pedagogia da autonomia: saberes necessários à prática educativa. 8a ed. São Paulo: Paz e Terra; 1998.

9. Bento B. A reinvenção do corpo: sexualidade e gênero na experiência transexual. Rio de Janeiro: Garamond; 2006.

10. Castel PH. Algumas reflexões para estabelecer a cronologia do "fenômeno transexual" (1910-1995). Revista Brasileira de História 2001; 21(41):77-111.

11. Arán M, Murta D, Lionço T. Transexualidade e saúde pública no Brasil. Cien Saude Colet 2009; 14(4):11411149.

12. Moscovici S. Representações Sociais: investigações em psicologia social. Petrópolis: Vozes; 2003. 
13. Almeida A. A pesquisa em representações sociais: uma discussão propedêutica. Revista Ser Social 2001; 9(1):129-158.

14. Jodelet D. Representações Sociais. Interdisciplinaridade e diversidade de paradigmas. In: Jodelet D. Recentes desenvolvimentos da noção de representações nas ciências sociais. Brasília: Thesaurus; 2009.

15. Alves-Mazzotti AJ. Representações Sociais: aspectos teóricos e aplicações à educação. Rev Múltiplas Leituras 2008; 1(1):18-43.

16. Sá CP. Núcleo Central das Representações Sociais. Petrópolis: Vozes; 1996.

17. Vergès P. Ensemble de programmes permettant l'analyse des evocations: manuel version 2. Aix-en-Provence: Lames; 2000.

18. Laqueur TW. Inventando o sexo: corpo e gênero dos gregos a Freud. Rio de Janeiro: Relume Dumará; 2001.

19. Shelley CV. Transpeople: repudiation, trauma, healing. Canada: University of Toronto Press Incorporated; 2008.

20. Lionço T. Atenção integral à saúde e diversidade sexual no Processo Transexualizador do SUS: avanços, impasses, desafios. Physis 2009; 19(1):43-63.

21. Ayres JR. Práticas educativas e prevenção de HIV/Aids: lições aprendidas e desafios atuais. Interface (Botucatu) 2002; 6(11):11-24.

Artigo apresentado em 01/08/2013

Aprovado em 25/08/2013

Versão final apresentada em 01/09/2013 